\title{
Recent advances in the knowledge of coronaviruses with special emphasis on severe acute respiratory syndrome coronavirus 2 (SARS-CoV-2)
}

\author{
Khushboo Irshad $^{1 *}$, Madeeha Mudassir ${ }^{1}$, Sheeba $\operatorname{Irshad}^{2}$, Mohammad Irshad ${ }^{3 *}$ \\ ${ }^{1}$ Department of Biochemistry, All India Institute of Medical Sciences, New Delhi, India. \\ ${ }^{2}$ Previously at Department of Emergency Medicine, All India Institute of Medical Sciences, New Delhi, India. \\ ${ }^{3}$ Previously at Department of Laboratory Medicine, All India Institute of Medical Sciences, New Delhi, India.
}

\begin{tabular}{l}
\hline ARTICLE INFO \\
\hline Article history: \\
Received on: September 23, 2020 \\
Accepted on: November 17, 2020 \\
Available online: January 17, 2021 \\
\hline
\end{tabular}

\section{Key words:}

Coronavirus,

Severe acute respiratory syndrome

coronavirus 2

COVID-19.

\begin{abstract}
COVID-19 continues to pose a global public health emergency several months after the first cases of severe acute respiratory syndrome coronavirus 2 (SARS-CoV-2) (then referred to as novel coronavirus [2019-nCoV]) infection were reported in Wuhan, China. Starting off as local infection, it has now affected most countries devastatingly while taking its toll on millions of people. So far, clinicians and researchers have derived biological understanding and treatment designs to tackle COVID-19 from the recently learned lessons during similar epidemics caused by coronaviruses, namely, SARS-CoV and Middle East respiratory syndrome coronavirus (MERS-CoV). However, COVID-19 has transformed into a pandemic surpassing the previously reported epidemics and requires a targeted therapy approach in addition to synchronized preventive measures. With the advent of new knowledge and developments on the subject of SARSCoV-2 almost every day, an update to the biological understanding of coronaviruses is necessary as well. This article presents a comprehensive review of SARS-CoV-2 biology, COVID-19 epidemiology, and therapeutic approaches for patients along with the major issues of concern. We cover the structure and infection mechanism of SARS-CoV-2 known till date, along with the common pathological findings and immune responses in patients. We also review the patterns of disease epidemiology in India and worldwide, the current therapeutic modalities as well as the possible strategies of prophylaxis and treatment that may be used for COVID-19 patients in the near future. Finally, we discuss a few challenges put forth by this pandemic in a developing country like India which need to be addressed immediately.
\end{abstract}

\section{INTRODUCTION}

Coronaviruses belong to a family of enveloped, single-stranded positive-sense RNA (+ssRNA) viruses which are known to infect a variety of hosts spanning humans as well as other mammals, birds, and vertebrates [1-3]. While the main manifestation of the viral disease is in the form of respiratory infection or enteric disease, coronaviruses have also been known to trigger hepatitis and neurologic illness in certain cases $[2,3]$ Up until now, infections by individual coronaviruses were believed to be species-specific, where the infection could be acute as well as persistent [3]. However, the recent outbreak of coronavirus-induced fatal pneumonia in Wuhan, China, in late 2019 and its transformation into a pandemic disease by early 2020 has put this notion to question, as the causal pathogen has been suggested to have a zoonotic origin and

*Corresponding Author

Khushboo Irshad

Department of Biochemistry,

All India Institute of Medical Sciences, New Delhi, India

E-mail:khushbooirshad@yahoo.com

Mohammad Irshad

Previously at Department of Laboratory Medicine,

All India Institute of Medical Sciences, New Delhi, India

E-mail: drirshad54@yahoo.com shares ancestry with bat coronavirus HKU9-1 [4]. The World Health Organization (WHO) has named this underlying novel coronavirus as severe acute respiratory syndrome coronavirus 2 (SARS-CoV-2), owing to its similarities to SARS-coronaviruses (SARS-related coronaviruses), while the disease has been termed as coronavirus disease 2019 or COVID-19 [5]. By early March 2020, COVID-19 was declared as a "public health emergency of international concern" by the WHO; and by late July, SARS-CoV-2 had infected $>16$ million people worldwide with at least 646,384 patients dead [6]. Henceforth, to assist the rapidly progressing research in this field, the ground understanding of coronavirus biology needs to be updated with the latest knowledge and developments emerging during the COVID-19 pandemic. Here, we review the various biological aspects of coronaviruses, especially in reference to the structure, imaging, and infection mechanism of SARSCoV-2; the patient immune response to SARS-CoV-2 followed by the epidemiology and therapeutic management of COVID-19; and finally, the major challenges posed by this disease.

\section{STRUCTURE, IMAGING, AND INFECTION MECHANISM OF SARS-COV-2}

Taxonomically, coronaviruses are classified under the sub-family of Coronavirinae which is included in the family Coronaviridae of the 
order Nidovirales $[1,7,8]$. The sub-family comprises of four genera, namely, Alphacoronavirus, Betacoronavirus, Gammacoronavirus, and Deltacoronavirus [1,8]. The classical genome of coronavirus is known to contain a single-stranded RNA approximately $30 \mathrm{~kb}$ in length with a 5 '-cap structure and a 3'-poly-A tail [1]. Sequence analysis of the recent SARS-CoV-2 virus has revealed that it is composed of the typical genome structure of coronaviruses which can be grouped under the cluster of beta coronaviruses that also includes SARS-CoV, MERS$\mathrm{CoV}$, and certain Bat-SARS-like coronaviruses [1,7,9]. Detailed phylogenetic analysis has, in fact, revealed a closer relationship of SARS-CoV-2 to Bat-SL-CoV ZC45 and Bat-SL-CoV ZXC21 [1,10], while another study has also suggested the zoonotic origin of SARSCoV-2 and its shared ancestry with bat coronavirus HKU9-1 [4].

Classically, ssRNA in coronaviruses is known to translate polyprotein $1 \mathrm{a} / 1 \mathrm{ab}(\mathrm{pp} 1 \mathrm{a} / \mathrm{pp} 1 \mathrm{ab})$ that encodes sixteen nonstructural proteins that enable the formation of a replication-transcription complex and lead to the production of subgenomic mRNAs [11]. Further, four structural proteins are known to be formed in coronaviruses that are essential for the process of infection and virion assembly [1]. In the case of SARS-CoV-2, the viral genome has been identified to be arranged in the following order: 5'-UTR-replicase complex (orf 1ab)-structural proteins (Spike(S)-Envelope(E)-Membrane(M)-Nucleocapsid(N))-3'-UTR and nonstructural open-reading frames [12]. Role of the structural proteins has been documented previously with regard to other coronaviruses. Briefly, the spikes on the viral surface constitute homotrimers of $\mathrm{S}$ proteins which facilitate the viral attachment to host cell receptors $[13,14]$. E protein is involved in viral pathogenesis and functions in virus assembly and release $[15,16]$. $M$ protein containing three transmembrane domains accounts for virion shape, membrane curvature, and binding with nucleocapsid $[17,18]$. N protein binds to Nsp3 protein to bind the genome to replication-transcription complex and enables the packaging of the encapsidated genome into virions [19-21]. $\mathrm{N}$ protein can also act as an interferon-antagonist and a viral-encoded repressor of RNA interference that aids viral replication [22].

Similar to the morphodiagnostic features of coronaviruses, SARS-CoV-2 particles have been observed to be spherical, with characteristic spike proteins protruding from the surface [23]. Prasad et al. revealed the detailed morphology and ultrastructure of SARSCoV-2 using transmission electron microscopy imaging. They documented the round shape of the virus having an average particle size of $70-80 \mathrm{~nm}$ and a cobbled surface structure with envelope projections that averaged $15 \pm 2 \mathrm{~nm}$ in size [23].

Following the recent COVID-19 outbreak and pandemic, research studies were taken up to identify the cellular receptor of SARS-CoV-2 on human cells. In one such study, cryo-electron microscopy imaging revealed that similar to the virus that caused the 2002 SARS outbreak, SARS-CoV-2 binds to angiotensin-converting enzyme 2 (ACE2) receptors on human cells using its spike proteins [24]. In another study, predictions using molecular modeling docking and structural bioinformatics indicated that cell-surface receptor glucose-regulated protein 78 might be a potential binding candidate available to the spike protein of SARS-CoV-2 particle [25]. Similarly, another molecular modeling study predicted the potential interaction between human CD26, an important immunoregulatory factor for virulence, and S1 domain of SARS-CoV-2 spike glycoprotein [26].

The potential mechanism employed by SARS-CoV-2 for intracellular entry in the host has been described as similar to the infection mechanism of SARS-CoV. It begins with the S protein present on the viral coat which contains a receptor-binding region with a high affinity toward extracellular domain of ACE2 receptor [27,28]. Upon binding, a cleavage occurs in $\mathrm{S}$ protein along dibasic arginine sites by the activity of host protease TMPRSS2 that results in S1 and S2 subunits. This is followed by S2-induced membrane fusion and internalization of the virus along with ACE2 through endocytosis in the cell [28].

\section{PATHOLOGICAL FINDINGS AND HOST IMMUNE RESPONSE IN COVID-19 PATIENTS}

Before the COVID-19 pandemic, the world had quite recently seen deadly outbreaks initiated by two coronaviruses named SARS-CoV and MERS-CoV, which, like SARS-CoV-2, were reported as zoonotic origin viruses that had crossed the species barrier [29]. Thereafter, comparisons between SARS-CoV-2, SARS-CoV, and MERS-CoV have indeed shown a lot of resemblances in terms of clinical symptoms which start from asymptomatic infection up till SARS [30,31].

Since the appearance of the first cases in Wuhan, China, in December 2019, various immunological and clinical features of COVID-19 infection and the associated respiratory illness have been under rigorous examination and research which continue to progress rapidly even now [29]. It is now established that COVID-19 infection can result in severe pneumonia which may become fatal in older patients with comorbidities such as cardiovascular diseases, chronic kidney disease, diabetes, malignancies, and liver diseases [32-34]. Typically, patients diagnosed with COVID-19 infection have presented with clinical presentations of fever, fatigue, dry cough, anorexia, myalgia, dyspnea, diarrhea, and headache [32,34,35]. Mostly, chest computed tomography scans of patients have shown bilateral multiple lobular and subsegmental areas of consolidation, and the median time from the onset of symptoms to intensive care unit (ICU) admission has been 10 days $[34,35]$. As checked at the time of ICU admission, the median partial pressure of oxygen has been seen to be $68 \mathrm{~mm} \mathrm{Hg}$ (interquartile range [IQR], 56-89), while the median partial pressure of oxygen to fraction of inspired oxygen ratio has been observed as $136 \mathrm{~mm} \mathrm{Hg}$ (IQR, 103-234) [34].

According to the many investigations done till date, the commonest abnormal laboratory findings of COVID-19 patients include elevated total neutrophils, decreased total lymphocytes, elevated serum interleukin-6 (IL-6), and increased C-reactive protein, apart from prolonged prothrombin time and increased lactate dehydrogenase $[9,32,34,35]$. These studies have suggested that similar to previous reports of SARS-CoV and MERS-CoV affected patients, COVID-19 patients may be associated with cellular immune deficiency, coagulation activation, myocardia injury, and hepatic and kidney damage [34]. In response to SARS-CoV-2 infection, the initial plasma levels of the cytokines IL-1 $\beta$, IL-1R $\alpha$, IL-7, IL-8, IL-9, IL-10, basic fibroblast growth factor, granulocyte colony-stimulating factor, granulocyte monocyte colony-stimulating factor, interferon-gamma (IFN $\gamma$ ), IP10, MCP1, MIP1A, MIP1B, platelet-derived growth factor, tumor necrosis factor- $\alpha$ (TNF- $\alpha$ ), and vascular endothelial growth factor in the patients have been found elevated relative to healthy controls [35]. In addition, patients admitted to ICU have shown elevated plasma concentrations of IL-2, IL-7, IL-10, GSCF, IP10, MCP1, MIP1A, and TNF- $\alpha$ than the non-ICU patients [35]. Hence, COVID-19 severity and progression have largely been attributed to the development of a highly pro-inflammatory condition in patient [36].

It has been hypothesized that, like SARS-CoV, SARS-CoV-2 possibly acts mainly on lymphocytes, particularly $\mathrm{T}$ lymphocytes [32,37]. Following infection with SARS-CoV-2, the virus particles are able to spread through respiratory mucosa and infect other cells, thereby 
generating a "cytokine storm" which constitutes a sequence of immune responses and disturbances in peripheral white blood cells and immune cells like lymphocytes. At times, such aggressive cytokine activity can lead to viral sepsis and inflammation-induced lung damage which can cause complications such as acute respiratory distress syndrome, septic shock, and even multiple organ failure, implying the need for early diagnosis and treatment in such critical cases $[32,36]$.

The human innate immune system usually identifies viral invasion in cells by recognizing molecular structures named pathogen-associated molecular patterns (PAMPs) [38,39]. This event is followed by activation of several signaling pathways such as activator protein 1 , nuclear factor $\mathrm{kB}$, interferon response factor 3 (IRF3), and IRF7. IRF3 and IRF7 are responsible for the synthesis of type I interferon (IFN- $\alpha$ and IFN- $\beta$ ), which carry out antiviral innate immune response by inhibition of viral replication and dissemination at an early stage [40]. However, in the case of SARS-CoV-2, an antiviral response by type I IFN has been found as suppressed [39]. Further, a significant portion of the human adaptive immune response to viral infections is formed by the T-cells which generate a substantial IFN- $\gamma$ response [37]. Chen et al. have recently shown that SARS-CoV-2 infection essentially decreases the count of $\mathrm{T}$ lymphocytes, especially $\mathrm{CD} 4^{+}$and $\mathrm{CD} 8^{+} \mathrm{T}$-cells, and reduces IFN- $\gamma$ secretion by $\mathrm{CD}^{+} \mathrm{T}$-cells. In fact, these two have been determined as potential immunological markers that correlate with the severity of disease in COVID-19 patients [37].

Even with the list of most common presenting symptoms of COVID-19, a pressing need was recognized to characterize the range of clinical presentations so as to enable early diagnosis, isolation, and management of the infected individuals. In one such attempt, it was found that the patients who presented with gastrointestinal symptoms of nausea, vomiting, and diarrhea at the time of testing were significantly more likely to test positive for COVID-19 than to test negative, whereas patients without these symptoms had equal chances of testing positive or negative [41]. The authors analyzed a multi-variable model using the known variables associated with a positive COVID-19 test outcome and inferred that, indeed, a presence of gastrointestinal symptoms led to a $70 \%$ increase in the risk of testing positive.

It is noteworthy that the manifestation of gastrointestinal symptoms in COVID-19 patients such as diarrhea, vomiting, and stomach ache $[42,43]$ can be justified by the expression of ACE2 receptors on the epithelial cells of the small intestine that can enable SARS-CoV-2 binding [44]. Furthermore, the occurrence of gastrointestinal symptoms has been reported exclusive of the respiratory symptoms albeit in rare cases [43]. Even so, these findings need to be substantiated in large groups of patients and cannot be called as primary symptoms of COVID-19 onset. Nonetheless, they do point to digestive system as being a candidate target organ for SARS-CoV-2. Therefore, it might be pertinent to combine gastrointestinal symptoms along with respiratory symptoms while diagnosing patients by their symptoms.

\section{EPIDEMIOLOGY OF COVID-19}

Early studies of COVID-19 (then referred to as 2019-nCoV - infected pneumonia) had confirmed the human-to-human transmission of this disease [33]. In one such study, Li et al. had studied the first 425 confirmed cases in Wuhan to determine the epidemiological profile of COVID-19. Although early in their inference, they did present some key factors responsible for disease transmission and possible management, varying from estimation of reproduction number, to determining the trends in incubation period and serial interval, to proposing possible management by isolation and medical observation of the exposed people for at least 14 days and a similar quarantine period for close contacts. The same parameters have been substantiated by other related studies [45]. These studies have estimated a reproduction number (R0) of 2.2-2.5, that is, each infected person can further transmit it to 2.2 other people. Incubation period, defined as the time duration between infection and appearance of symptoms, has been reported to be ranging from 1 to 14 days with a mean of 5.2 days. Another important epidemiological factor in determining the transmission is the serial interval which is the time between onsets of symptoms in successive cases. This is estimated by studying the time of illness onset in infectorinfectee (primary and secondary cases) pairs. The mean serial interval in these studies and others was reported differently as 7.4 days [33], 5.8 days [45], and 3.96 [46], with the latter group reporting R0 of 1.32. Nevertheless, however, varied these estimates be, a value $>1$ for R0 indicates an increase in epidemic and therefore, the control measures must aim to bring it down to $<1$. Further, when the serial interval is lesser than the incubation period, that is, the secondary cases (infectee) show symptoms before the primary (infector) case, the disease is said to have significant pre-symptomatic transmission. This attenuates the success of control measures that are set up after onset of symptoms, such as isolation, contact tracing, and use of face masks. Case studies have revealed symptomatic, pre-symptomatic, and even asymptomatic transmission of COVID-19 [6,45-49].

In India, the first confirmed positive case of COVID-19 was recorded on January 30, 2020, that of a student who returned to Kerala from Wuhan, China [50,51]. By April 9, 2020, more than a hundred cases had been confirmed in the country, with the majority showing a travel history to the affected parts of the world. However, in spite of the predisposition of India as the second-most populous country and a developing nation with limited medical facilities (especially in the rural areas), the number of deaths resulting from COVID-19 have been less as compared to other nations. This could be possibly linked to a younger population in India at the present time [50,52]. The current epidemiological scenario in India has been displayed in Figure 1. As per the Ministry of Health and Family Welfare, India, (https://www.mohfw.gov.in) on October 27, 2020, the total number of active COVID-19 cases stand at 625,857 (7.9\%), while the cured or discharged patients sum up to 7,201,070 cumulatively. The cumulative number of deaths confirmed as a result of COVID-19 in India has been documented as 119,502 which is $1.5 \%$ of the total cases till date

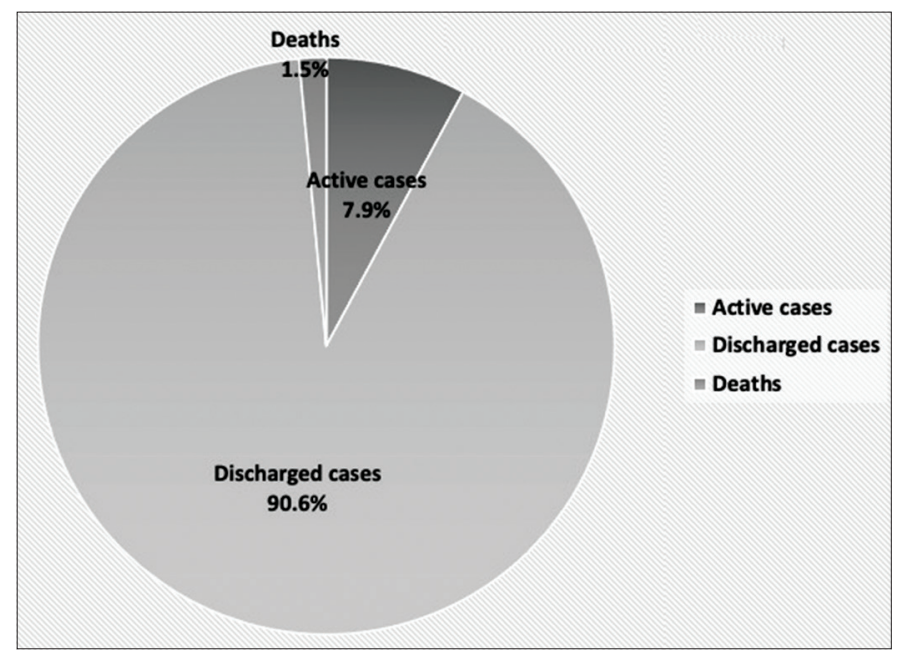

Figure 1: Distribution of active cases, discharged cases, and deaths due to COVID-19 in India as on October 27, 2020 [Source: https://www.mohfw.gov.in/]. 
[Figure 1]. On the other hand, the cumulative count of deaths across the world corresponds to $2.7 \%(1,152,604)$ of the total confirmed cases $(42,966,344)$ in the world as per WHO [6]. Upon checking the statewise distribution of cases in India, it may be noted that the maximum active cases on October 27,2020 exist in Maharashtra $(134,657 ; 21.5 \%)$, followed by Kerala $(93,848 ; 15 \%)$, Karnataka (75,442; 12.1\%), West Bengal (37,190; 5.9\%), Tamil Nadu $(29,268$; 4.7\%), Andhra Pradesh (28,770; 4.6\%), Uttar Pradesh (26,652; 4.3\%), Delhi $(25,786 ; 4.1 \%)$, Chhattisgarh $(22,093 ; 3.5 \%)$, and Telangana $(17,890 ; 2.9 \%)$ [53]. However, it should be pointed out that the coverage and frequency of laboratory surveillance for SARS-CoV-2 by the Indian Council of Medical Research (ICMR) have improved continually over time. COVID-19 in India was reported more among men and older individuals and was common among nearby contacts of the patients [51]. Nevertheless, as a nation having the second highest number of confirmed cases in the world at present [6], India is in a situation that warrants continuous development of surveillance tools and strategies at both national and state levels.

\section{MODES OF TRANSMISSION OF SARS-COV-2}

In a scientific brief published by the WHO [54], COVID-19 transmission through contact routes as well as respiratory droplets has been highlighted [30,33,35,55-57]. Respiratory droplets are droplet particles $>5-10 \mu \mathrm{m}$ in diameter and the transmission can occur in people within $1 \mathrm{~m}$ of an infected person who shows respiratory symptoms (e.g., coughing and sneezing). This is direct transmission. Indirect transmission occurs through fomites within the immediate environment of the infected person or through items used on the infected person (e.g., thermometer and stethoscope) [58].

Although airborne transmission has not been reported in the case of COVID19, there is possibility of it being transmitted through aerosols which might be generated during healthcare support to the patient such as ventilation and intubation. Aerosol transmission occurs through droplets $<5 \mu \mathrm{m}$ in diameter (called as droplet nuclei) which are capable of being in air for longer times and can be transmitted over greater distances than respiratory droplets. However, a more recent study was done to estimate the respiratory virus shedding in the exhaled breath of 246 patients having respiratory illnesses, including coronavirus infections. It provided evidence that respiratory droplets from coronavirus-infected patients can remain in the exhaled air for at least $30 \mathrm{~min}$ [59].

There are reports of viral RNA or live infectious virus being present in fecal matter, suggesting a possible fecal-oral route of transmission $[60,61]$. In fact, fecal polymerase chain reaction (PCR) testing was found to be as accurate as the PCR detection from the respiratory specimen in a study done by Tian et al. [62]. It has also been seen that SARS-CoV-2 particles survive longer in the gastrointestinal tract than in the respiratory tract. Xu et al. [63] detected viral RNA in rectal swabs of pediatric patients even after their nasopharyngeal testing had become negative, signifying the importance of rectal swab-testing over nasopharyngeal swab-testing while determining the efficacy of treatment. Thus, the role of the digestive system in COVID-19 patients and its possibility as a potential transmission route needs to be addressed with utmost attention for better disease management and checking transmission [42].

Based on these and other reports, the WHO has issued guidelines for the people looking after COVID-19 patients, including droplet and contact precautions; and airborne precautions in case of possible aerosol-generating procedures and support treatment procedures [6,54]. Similarly, it has laid emphasis on the significance of frequent hand hygiene, environmental cleaning, and disinfection, need for physical distancing and avoiding close contact with people displaying fever or respiratory symptoms.

\section{THERAPEUTIC MANAGEMENT OF COVID-19}

Limited knowledge about the virus poses a challenge to developing effective therapeutics against SARS-CoV-2. However, with the viral genome sequence (GenBank ID: MN908947.3) information available, the identification of druggable targets provides a ray of hope for COVID-19 patients. While there is an urgency to tackle the disease and its complications by scaling up rapid diagnosis and therapeutics, there is an equally commanding need to develop effective antiviral therapy for long-term management and prevention of such outbreaks in the future.

Convalescent plasma (CP) therapy has been hailed as the wonder savior in this regard. It is a type of passive antibody therapy during which a susceptible individual is administered antibodies to prevent or treat an infectious disease [64]. These antibodies are against the disease-causing agent. In the case of SARS-CoV-2, these antibodies are likely to neutralize the virus or might possibly activate phagocytosis or antibody-dependent cellular cytotoxicity. These passive antibodies can be derived from human convalescent sera of recent patients who have fully recovered from the disease or can be generated in certain genetically modified animal hosts which can produce human antibodies. Of these, human convalescent sera only can be immediately made available for use. It will, however, take several months' time to raise antibodies in hosts or produce this using recombinant DNA technology or produce a potential vaccine to combat this threat.

CP therapy has been earlier used successfully in the treatment of SARS, MERS, and $2009 \mathrm{H} 1 \mathrm{~N} 1$ patients with adequate efficacy and safety [65-68] and has also been reported to show improvements in severe COVID-19 patients [69,70]. In a study led by Duan et al. [69], convalescent sera from COVID-19 recovered patients was used in 10 severe COVID-19 patients and shown to improve symptoms such as fever, cough, chest pain, and difficulty in breathing within 1-3 days after CP transfusion. The efficacy of this approach is reinforced by the fact that two of the three patients who received mechanical ventilation were weaned off to high-flow nasal cannula and patient earlier on conventional low-flow nasal cannula oxygenation was shifted to intermittent oxygenation. There was an improvement in clinical outcomes of patients when compared to a control cohort treated at the same hospital. Seven of the ten enrolled patients showed a positive result for reverse transcription-PCR done for SARS-CoV-2 RNA before CP transfusion, while it was negative in three patients. It reduced to undetectable level in almost all positive patients within 2-6 days after CP therapy.

At present, there are no drugs approved by the Food and Drug Administration for prevention or treatment of COVID-19. However, there are studies underway aiming to employ novel or already available pharmacologic agents for inhibiting the growth of SARSCoV-2 [71,72]. Remdesivir is a drug which is known to inhibit viral replication by incorporating into nascent RNA resulting in pre-mature termination $[73,74]$. In-vitro experiments by Wang et al. on Vero E6 cells infected with SARS-CoV-2 showed effects post virus entry into the cells [73]. The same group also reported chloroquine to be effective against the virus at both entry and post-entry stages of SARS$\mathrm{CoV}-2$. It increases endosomal $\mathrm{pH}$, affects the fusion of virus and cell, and also interferes with receptor glycosylation. While chloroquine is an age-old drug used in cases of malaria and has been repurposed to treat COVID-19 patients with limited success, remdesivir has been in 
fast-track stages of the clinical trial, while its safety and efficacy as an anti-SARS-CoV-2 therapeutic candidate remains to be determined [73]. Several other drugs are currently in clinical trials of prophylaxis (preexposure and post-exposure) or treatment of COVID-19 in a fast-track and parallel manner, raising the hope of rapid progress against this pandemic [72].

\section{FUTURE CHALLENGES IN THE CONTEXT OF DEVELOPING COUNTRIES SUCH AS INDIA}

In view of a serious health hazard created the world over by this pandemic COVID-19 infection, there is an urgency to address some important issues related to it. The first important aspect relates to an early realization of COVID-19 infection on the basis of clinical symptoms. Although this appears a bit difficult due to the close resemblance among symptoms produced during several other respiratory viral infections, including common flu, H1N1 infection, SARS, MERS, and others [75,76]. However, the development of an algorithm of signs for clinical examination of the subjects may give certain thin lines of evaluation to pick COVID-19 at an early stage before the patient advances to the risk of sepsis and high fatality. Besides, it may also prevent disease transmission to close contacts and its further spread in the vicinity. Simultaneously, there is an urgency to develop credible, fast, and easy-to-perform laboratory procedures for an accurate diagnosis of COVID-19. At present, the use of PCRbased assays does not cope up the urgency of early diagnosis, while the rapid antibody test does not deliver a specific diagnosis. Whereas antibody tests have a questionable status, PCR assays are lengthy and need specialized laboratory set-up. In a country like India, it is not possible in all hospitals to conduct PCR, particularly in peripheral hospitals where patients undergo treatment. Now it may be possible to develop enzyme immunoassay systems for mass screening of populations yielding a final and confirmative detection of $\operatorname{IgM} / \mathrm{IgG}$ anti-SARS-CoV-2 antibodies, thereby enabling early and accurate detection of the infection. Expression of a specified genomic region of SARS-CoV-2 genome and the use of the peptide as an antigen for the development of a sandwich type of ELISA may solve many problems. All these actions need steps at war-footing to tackle the current crisis.

On a similar line, various authors support extensive use of convalescent plasma therapy for immediate neutralization of the replicating virus in COVID-19 patients, as well as the initiation of new trials of recently developed antiviral drugs which have been used in case of other viruses such as SARS-CoV and hepatitis virus $\mathrm{C}$ infection in the last one decade [77-79]. Placing hopes on chloroquine, an anti-malarial drug, to act effectively may not be promising. In addition, the development of an effective vaccine may prove to be a long-term goal which could take several months [72]. While one ardently hopes for a fruitful vaccine with maximal efficacy, the existence of numerous strains of the virus as well as the possibility of rapid genomic variations during in situ multiplication of virus, as the same has been documented in the case of many other viruses, is quite worrisome.

It is hereby imperative to discuss the various trials of different preventive vaccines that have begun worldwide, including in India, although the current treatment strategy primarily focuses on the management of COVID and its associated severities. In the global landscape, six main types of COVID-19 vaccine candidates are being worked upon which can be categorized as: protein subunit ( 7 clinical and 50 preclinical), recombinant viral vectored (4 clinical and 38 preclinical), nucleic acidbased (10 clinical and 27 preclinical), virus-like particles ( 1 clinical and 12 preclinical), inactivated virus ( 5 clinical and 9 preclinical), and live attenuated virus ( 3 preclinical). The nucleic acid-based platform comprises of both mRNA vaccines ( 6 clinical and 16 preclinical) as well as plasmid DNA vaccines (4 clinical and 11 preclinical) [80].

The frontrunner vaccine candidates can be further discussed in detail. A study published in The Lancet in July 2020 demonstrated the efficacy and safety of an adenovirus-vectored vaccine (ChAdOx1 nCoV-19) that expresses SARS-CoV-2 spike protein [81]. The preliminary findings from this study support the ongoing phase III trials that have begun in the UK, Brazil, South Africa, and USA. This vaccine has also been found to prevent SARS-CoV-2 pneumonia in rhesus macaques by triggering a balanced Th1/Th2 humoral and cellular immune response [82]. Another candidate is $\mathrm{Ad} 5-\mathrm{nCoV}$, an adenoviral (nonreplicating) vaccine candidate developed by CanSino Biologics Inc., Beijing Institute of Biotechnology, which expresses S protein and is administered as a single dose of IM injection. At present, going through phases I and II, the phase II studies of the vaccine are mainly being conducted in China and Canada [80]. Another frontrunner vaccine candidate, mRNA-1273, has been co-developed by Moderna Inc. and the National Institute of Allergy and Infectious Diseases to investigate its preventive action on COVID-19 [83]. It consists of a lipid nanoparticle formulation with an mRNA encoding the protein S-2P, a surface spike protein which helps in the entry of SARS-CoV-2 into a cell. After its successful evaluation in the study participants, $\mathrm{NIH}$ initiated its phase III trial. Other prospective vaccine candidates that are undergoing phase III trials in various nations include PiCoVacc (Sinovac Biotech), BNT162b1 (BioNTech, Pfizer, Fosun Pharma), BBIBP-CorV (Sinopharm, Beijing Institute of Biological Products Co. Ltd.), COVID-19 vaccine (Sinopharm, Wuhan Institute of Biological Products Co. Ltd.), and INO-4800 (Inovio Pharmaceuticals, International Vaccine Institute) [80].

Finally, India does not lag behind in its efforts to develop a potential vaccine candidate and has launched the human trial of its first COVID-19 vaccine named as "COVAXIN" ${ }^{\mathrm{TM}}$." Developed by Bharat Biotech in collaboration with ICMR - National Institute of Virology, it is a form of the inactivated vaccine and has been approved for phase I and II trials after it showed promising results in part 1 of its phase I trial [84]. However, it may be important to point out here that while parallel and overlapping investigations of potent COVID-19 vaccines is the global need of the hour, previous scientific knowledge and implementation strategies should be constant guidance while furthering the best candidates during clinical trial, approval, manufacture, distribution, and final application in any population.

Last but not least, the administrative strategies in any given state or country have proven to be critical in the control of the pandemic and need to be based on scientific deductions. The present focus lies on the construction of mathematical models aimed at impeding an unbearable burden on the health care infrastructure [47]. In India, the impact of various lockdown strategies on COVID-19 transmission has been assessed [85]. A framework of differential equations was created by integrating the reported number of cases from 14 nations. It indicated that implementation of a stringent lockdown for a minimum of 21 days is essential to significantly lower virus transmission and may be prolonged up to 42 days. Although different models based on varying mathematical assumptions have emerged in separate areas, lockdown strategies and physical distancing remain one of the most effective ways of curbing exponential transmission of COVID-19.

Henceforth, perceiving this pandemic as a common world challenge, scientists, and administrators must put forth combined efforts and synchronized decision-making to address the global crisis. 


\section{CONCLUSION}

We have reviewed the most up to date research pertaining to structure and infection mechanism of SARS-CoV-2 as well as immunopathology, epidemiology, and therapy of COVID-19 patients. In addition, we discuss the current challenges being faced in the COVID-19 era in a developing nation like India. This review may help both researchers and clinicians in their understanding of the biology of the novel coronavirus SAR-CoV-2 as well as in their strive for better therapeutic designs for COVID-19 patients.

\section{ACKNOWLEDGMENT}

We are grateful for the infrastructure provided by All India Institute of Medical Sciences, New Delhi, India, for conducting this study.

\section{AUTHORS' CONTRIBUTIONS}

KI, MM, and SI have contributed in the compilation of data and MI has contributed in the preparation and editing of the manuscript.

\section{FUNDING}

There is no funding to report.

\section{AUTHOR DISCLOSURE STATEMENT}

The authors declare that there are no conflicts of interest among them related to this study.

\section{REFERENCES}

1. Chen Y, Liu Q, Guo D. Emerging coronaviruses: Genome structure, replication, and pathogenesis. J Med Virol 2020;92:418-23.

2. Lai MM. Coronaviridae: The Viruses and Their Replication; GoogleBooks-ID: aSsOGwAACAAJ.

3. Masters PS. The molecular biology of coronaviruses. Adv Virus Res 2006;66:193-292.

4. Xu X, Chen P, Wang J, Feng J, Zhou H, Li X, et al. Evolution of the novel coronavirus from the ongoing Wuhan outbreak and modeling of its spike protein for risk of human transmission. Sci China Life Sci 2020;63:457-60.

5. Ul Qamar MT, Alqahtani SM, Alamri MA, Chen L-L. Structural basis of SARS-CoV-2 3CLpro and anti-COVID-19 drug discovery from medicinal plants. J Pharm Anal 2020;10:313-9.

6. Coronavirus Disease; 2019. Available from: https://www.who.int/ emergencies/diseases/novel-coronavirus-2019. [Last accessed on 2020 May 05].

7. Coronaviridae Study Group of the International Committee on Taxonomy of Viruses. The species severe acute respiratory syndrome-related coronavirus: Classifying 2019-nCoV and naming it SARS-CoV-2. Nat Microbiol 2020;5:536-44.

8. Xu J, Zhao S, Teng T, Abdalla AE, Zhu W, Xie L, et al. Systematic comparison of two animal-to-human transmitted human coronaviruses: SARS-CoV-2 and SARS-CoV. Viruses 2020;12:244.

9. Zhou P, Yang XL, Wang XG, Hu B, Zhang L, Zhang W, et al. A pneumonia outbreak associated with a new coronavirus of probable bat origin. Nature 2020;579:270-3.

10. Lai CC, Shih TP, Ko WC, Tang HJ, Hsueh PR. Severe acute respiratory syndrome coronavirus 2 (SARS-CoV-2) and coronavirus disease-2019 (COVID-19): The epidemic and the challenges. Int J Antimicrob Agents 2020;55:105924.

11. Snijder EJ, van der Meer Y, Zevenhoven-Dobbe J, Onderwater JJM, van der Meulen J, Koerten HK, et al. Ultrastructure and origin of membrane vesicles associated with the severe acute respiratory syndrome coronavirus replication complex. J Virol 2006;80:5927-40.

12. Wang $\mathrm{C}$, Liu $\mathrm{Z}$, Chen $\mathrm{Z}$, Huang $\mathrm{X}, \mathrm{Xu} \mathrm{M}, \mathrm{He} \mathrm{T}$, et al. The establishment of reference sequence for SARS-CoV-2 and variation analysis. J Med Virol 2020;92:667-74.

13. Beniac DR, Andonov A, Grudeski E, Booth TF. Architecture of the SARS coronavirus prefusion spike. Nat Struct Mol Biol 2006;13:751-2.

14. Delmas B, Laude H. Assembly of coronavirus spike protein into trimers and its role in epitope expression. J Virol 1990;64:5367-75.

15. DeDiego ML, Alvarez E, Almazán F, Rejas MT, Lamirande E, Roberts A, et al. A severe acute respiratory syndrome coronavirus that lacks the $\mathrm{E}$ gene is attenuated in vitro and in vivo. J Virol 2007;81:1701-13.

16. Nieto-Torres JL, DeDiego ML, Verdiá-Báguena C, JimenezGuardeño JM, Regla-Nava JA, Fernandez-Delgado R, et al. Severe acute respiratory syndrome coronavirus envelope protein ion channel activity promotes virus fitness and pathogenesis. PLoS Pathog 2014;10:e1004077.

17. Nal B, Chan C, Kien F, Siu L, Tse J, Chu K, et al. Differential maturation and subcellular localization of severe acute respiratory syndrome coronavirus surface proteins S, M and E. J Gen Virol 2005;86:1423-34.

18. Neuman BW, Kiss G, Kunding AH, Bhella D, Baksh MF, Connelly S, et al. A structural analysis of M protein in coronavirus assembly and morphology. J Struct Biol 2011;174:11-22.

19. Chang C, Sue SC, Yu T, Hsieh CM, Tsai CK, Chiang YC, et al. Modular organization of SARS coronavirus nucleocapsid protein. J Biomed Sci 2006;13:59-72.

20. Fehr AR, Perlman S. Coronaviruses: An overview of their replication and pathogenesis. Methods Mol Biol 2015;1282:1-23.

21. Hurst KR, Koetzner CA, Masters PS. Identification of in vivointeracting domains of the murine coronavirus nucleocapsid protein. J Virol 2009;83:7221-34.

22. Cui L, Wang H, Ji Y, Yang J, Xu S, Huang X, et al. The nucleocapsid protein of coronaviruses acts as a viral suppressor of RNA silencing in mammalian cells. J Virol 2015;89:9029-43.

23. Prasad S, Potdar V, Cherian S, Abraham P, Basu A, ICMR-NIV NIC Team. Transmission electron microscopy imaging of SARS-CoV-2. Indian J Med Res 2020;151:241-3.

24. Yan R, Zhang Y, Li Y, Xia L, Guo Y, Zhou Q. Structural basis for the recognition of SARS-CoV-2 by full-length human ACE2. Science 2020;367:1444-8

25. Ibrahim IM, Abdelmalek DH, Elshahat ME, Elfiky AA. COVID-19 spike-host cell receptor GRP78 binding site prediction. J Infect 2020;80:554-62.

26. Vankadari N, Wilce JA. Emerging WuHan (COVID-19) coronavirus: Glycan shield and structure prediction of spike glycoprotein and its interaction with human CD26. Emerg Microbes Infect 2020;9:601-4.

27. Letko M, Marzi A, Munster V. Functional assessment of cell entry and receptor usage for SARS-CoV-2 and other lineage B betacoronaviruses. Nat Microbiol 2020;5:562-9.

28. South AM, Diz DI, Chappell MC. COVID-19, ACE2, and the cardiovascular consequences. Am J Physiol Heart Circ Physiol 2020;318:H1084-90.

29. Liu J, Zheng X, Tong Q, Li W, Wang B, Sutter K, et al. Overlapping and discrete aspects of the pathology and pathogenesis of the emerging human pathogenic coronaviruses SARS-CoV, MERS-CoV, and 2019-nCoV. J Med Virol 2020;92:491-4.

30. Chan JF, Yuan S, Kok KH, To KK, Chu H, Yang J, et al. A familial cluster of pneumonia associated with the 2019 novel coronavirus indicating person-to-person transmission: A study of a family cluster. Lancet 2020;395:514-23.

31. Zhu N, Zhang D, Wang W, Li X, Yang B, Song J, et al. A novel coronavirus from patients with pneumonia in China, 2019. N Engl J Med 2020;382:727-33. 
32. Chen $\mathrm{N}$, Zhou $\mathrm{M}$, Dong $\mathrm{X}, \mathrm{Qu} \mathrm{J}$, Gong $\mathrm{F}$, Han $\mathrm{Y}$, et al. Epidemiological and clinical characteristics of 99 cases of 2019 novel coronavirus pneumonia in Wuhan, China: A descriptive study. Lancet 2020;395:507-13.

33. Li Q, Guan X, Wu P, Wang X, Zhou L, Tong Y, et al. Early transmission dynamics in Wuhan, China, of novel coronavirusinfected pneumonia. N Engl J Med 2020;382:1199-207.

34. Wang $\mathrm{D}, \mathrm{Hu} \mathrm{B}, \mathrm{Hu} \mathrm{C}$, Zhu F, Liu X, Zhang J, et al. Clinical characteristics of 138 hospitalized patients with 2019 novel coronavirus-infected pneumonia in Wuhan, China. JAMA 2020;323:1061-9.

35. Huang C, Wang Y, Li X, Ren L, Zhao J, Hu Y, et al. Clinical features of patients infected with 2019 novel coronavirus in Wuhan, China. Lancet 2020;395:497-506.

36. Prompetchara E, Ketloy C, Palaga T. Immune responses in COVID-19 and potential vaccines: Lessons learned from SARS and MERS epidemic. Asian Pac J Allergy Immunol 2020;38:1-9.

37. Chen G, Wu D, Guo W, Cao Y, Huang D, Wang H, et al. Clinical and immunological features of severe and moderate coronavirus disease 2019. J Clin Invest 2020;130:2620-9.

38. Irshad M, Gupta P, Irshad K. Immunopathogenesis of liver injury during hepatitis c virus infection. Viral Immunol 2019;32:112-20.

39. Rokni M, Ghasemi V, Tavakoli Z. Immune responses and pathogenesis of SARS-CoV-2 during an outbreak in Iran: Comparison with SARS and MERS. Rev Med Virol 2020;30:e2107.

40. Deng X, van Geelen A, Buckley AC, O’Brien A, Pillatzki A, Lager KM, et al. Coronavirus endoribonuclease activity in porcine epidemic diarrhea virus suppresses Type I and Type III interferon responses. J Virol 2019;93:e02000-18.

41. Nobel YR, Phipps M, Zucker J, Lebwohl B, Wang TC, Sobieszczyk ME, et al. Gastrointestinal symptoms and coronavirus disease 2019: A case-control study from the United States. Gastroenterology 2020;159:373-5.e2.

42. Rokkas T. Gastrointestinal involvement in COVID-19: A systematic review and meta-analysis. Ann Gastroenterol 2020;33:355-65.

43. Pan $\mathrm{L}, \mathrm{Mu} \mathrm{M}$, Yang $\mathrm{P}$, Sun $\mathrm{Y}$, Wang R, Yan J, et al. Clinical characteristics of COVID-19 patients with digestive symptoms in Hubei, China: A descriptive, cross-sectional, multicenter study. Am J Gastroenterol 2020;115:766-73.

44. Hamming I, Timens W, Bulthuis M, Lely A, Navis G, van Goor H. Tissue distribution of ACE2 protein, the functional receptor for SARS coronavirus. A first step in understanding SARS pathogenesis. J Pathol 2004;203:631-7.

45. He X, Lau EH, Wu P, Deng X, Wang J, Hao X, et al. Temporal dynamics in viral shedding and transmissibility of COVID-19. Nat Med 2020;26:672-5.

46. Du Z, Xu X, Wu Y, Wang L, Cowling BJ, Meyers LA. Serial interval of COVID-19 among publicly reported confirmed cases. Emerg Infect Dis 2020;26:(6):1341-3.

47. Kucharski AJ, Russell TW, Diamond C, Liu Y, Edmunds J, Funk S, et al. Early dynamics of transmission and control of COVID-19: A mathematical modelling study. Lancet Infect Dis 2020;20:553-8.

48. Rothe C, Schunk M, Sothmann P, Bretzel G, Froeschl G, Wallrauch C, et al. Transmission of 2019-nCoV infection from an asymptomatic contact in Germany. N Engl J Med 2020;382:970-1.

49. Kassem AM, Talaat H, Shawky S, Fouad R, Amer K, Elnagdy T, et al. SARS-CoV-2 infection among healthcare workers of a gastroenterological service in a tertiary care facility. Arab J Gastroenterol 2020;21:151-5.

50. Kaushik S, Kaushik S, Sharma Y, Kumar R, Yadav JP. The Indian perspective of COVID-19 outbreak. Virus Dis 2020;31:146-53.

51. ICMR COVID Study Group (In Alphabetical Order: Abraham P, Aggarwa N, Babu GR, Barani S, Bhargava B, Bhatnagar T. Laboratory surveillance for SARS-CoV-2 in India: Performance of testing and descriptive epidemiology of detected COVID-19, January 22 -April 30, 2020. Indian J Med Res 2020;151:424.

52. Kakar A, Nundy S. COVID-19 in India. J R Soc Med 2020;113:232-3.

53. Home Ministry of Health and Family Welfare GOI. Available from: https://www.main.mohfw.gov.in. [Last accessed on 2020 Oct 28].

54. Modes of Transmission of Virus Causing COVID-19: Implications for IPC Precaution Recommendations. Available from: https://www. who.int/news-room/commentaries/detail/modes-of-transmissionof-virus-causing-covid-19-implications-for-ipc-precautionrecommendations. [Last accessed on 2020 May 05].

55. Burke RM, Midgley CM, Dratch A, Fenstersheib M, Haupt T, Holshue $\mathrm{M}$, et al. Active monitoring of persons exposed to patients with confirmed COVID-19-United States, January-February 2020. MMWR Morb Mortal Wkly Rep 2020;69:245-6.

56. Liu J, Liao X, Qian S, Yuan J, Wang F, Liu Y, et al. Community transmission of severe acute respiratory syndrome coronavirus 2 , Shenzhen, China, 2020. Emerg Infect Dis 2020;26:1320-3.

57. Report of the WHO-China Joint Mission on Coronavirus Disease 2019 (COVID-19). Available from: https://www.who.int/publicationsdetail/report-of-the-who-china-joint-mission-on-coronavirus-disease2019-(covid-19). [Last accessed on 2020 May 05].

58. Ong SW, Tan YK, Chia PY, Lee TH, Ng OT, Wong MS, et al. Air, surface environmental, and personal protective equipment contamination by severe acute respiratory syndrome coronavirus 2 (SARS-CoV-2) from a symptomatic patient. JAMA 2020;323:1610-2.

59. Leung NH, Chu DK, Shiu EY, Chan KH, McDevitt JJ, Hau BJ, et al. Respiratory virus shedding in exhaled breath and efficacy of face masks. Nat Med 2020;26:676-80.

60. Gu J, Han B, Wang J. COVID-19: Gastrointestinal manifestations and potential fecal-oral transmission. Gastroenterology 2020;158:1518-9.

61. Hindson J. COVID-19: Faecal-oral transmission? Nat Rev Gastroenterol Hepatol 2020;17:259.

62. Tian Y, Rong L, Nian W, He Y. Review article: Gastrointestinal features in COVID-19 and the possibility of faecal transmission. Aliment Pharmacol Ther 2020;51:843-51.

63. Xu Y, Li X, Zhu B, Liang H, Fang C, Gong Y, et al. Characteristics of pediatric SARS-CoV-2 infection and potential evidence for persistent fecal viral shedding. Nat Med 2020;26:502-5.

64. Casadevall A, Pirofski LA. The convalescent sera option for containing COVID-19. J Clin Invest 2020;130:1545-8.

65. Cheng Y, Wong R, Soo YO, Wong WS, Lee CK, Ng MH, et al. Use of convalescent plasma therapy in SARS patients in Hong Kong. Eur J Clin Microbiol Infect Dis 2005;24:44-6.

66. Hung IF, To KK, Lee CK, Lee KL, Chan K, Yan WW, et al. Convalescent plasma treatment reduced mortality in patients with severe pandemic influenza A (H1N1) 2009 virus infection. Clin Infect Dis 2011;52:447-56.

67. Ko JH, Seok H, Cho SY, Ha YE, Baek JY, Kim SH, et al. Challenges of convalescent plasma infusion therapy in Middle East respiratory coronavirus infection: A single centre experience. Antivir Ther (Lond) 2018;23:617-22.

68. Zhou B, Zhong N, Guan Y. Treatment with convalescent plasma for influenza A (H5N1) infection. N Engl J Med 2007;357:1450-1.

69. Duan K, Liu B, Li C, Zhang H, Yu T, Qu J, et al. Effectiveness of convalescent plasma therapy in severe COVID-19 patients. Proc Natl Acad Sci U S A 2020;117:9490-6.

70. Shen C, Wang Z, Zhao F, Yang Y, Li J, Yuan J, et al. Treatment of 5 critically Ill patients with COVID-19 with convalescent plasma. JAMA 2020;323:1582-9.

71. Giudicessi JR, Noseworthy PA, Friedman PA, Ackerman MJ. Urgent guidance for navigating and circumventing the QTc-prolonging and torsadogenic potential of possible pharmacotherapies for coronavirus disease 19 (COVID-19). Mayo Clin Proc 2020;95:1213-21.

72. Therapeutic Options for COVID-19 Patients CDC. Available from: 
https://www.cdc.gov/coronavirus/2019-ncov/hcp/therapeuticoptions.html. [Last accessed on 2020 May 05].

73. Wang M, Cao R, Zhang L, Yang X, Liu J, Xu M, et al. Remdesivir and chloroquine effectively inhibit the recently emerged novel coronavirus (2019-nCoV) in vitro. Cell Res 2020;30:269-71.

74. Yao X, Ye F, Zhang M, Cui C, Huang B, Niu P, et al. In vitro antiviral activity and projection of optimized dosing design of hydroxychloroquine for the treatment of severe acute respiratory syndrome coronavirus 2 (SARS-CoV-2). Clin Infect Dis 2020;71:732-9.

75. Hendrickson CM, Matthay MA. Viral pathogens and acute lung injury: Investigations inspired by the SARS epidemic and the 2009 H1N1 influenza pandemic. Semin Respir Crit Care Med 2013;34:475-86.

76. Xie M, Chen Q. Insight into 2019 novel coronavirus an updated interim review and lessons from SARS-CoV and MERS-CoV. Int J Infect Dis 2020;94:119-24.

77. Chen YW, Yiu CP, Wong KY. Prediction of the SARS-CoV-2 (2019$\mathrm{nCoV}$ ) 3C-like protease (3CL pro) structure: Virtual screening reveals velpatasvir, ledipasvir, and other drug repurposing candidates. F1000Res 2020;9:129.

78. Gordon CJ, Tchesnokov EP, Woolner E, Perry JK, Feng JY, Porter DP, et al. Remdesivir is a direct-acting antiviral that inhibits RNAdependent RNA polymerase from severe acute respiratory syndrome coronavirus 2 with high potency. J Biol Chem 2020;295:6785-97.

79. Ju J, Kumar S, Li X, Jockusch S, Russo JJ. Nucleotide analogues as inhibitors of viral polymerases. BioRxiv 2020;2020:927574.

80. Jeyanathan M, Afkhami S, Smaill F, Miller MS, Lichty BD, Xing Z. Immunological considerations for COVID-19 vaccine strategies. Nat Rev Immunol 2020;20:615-32.
81. Folegatti PM, Ewer KJ, Aley PK, Angus B, Becker S, BelijRammerstorfer S. Safety and immunogenicity of the ChAdOx1 nCoV-19 vaccine against SARS-CoV-2: A preliminary report of a phase 1/2, single-blind, randomised controlled trial. Lancet 2020;396:467-78.

82. van Doremalen N, Lambe T, Spencer A, Belij-Rammerstorfer S, Purushotham JN, Port JR, et al. ChAdOx1 nCoV-19 vaccine prevents SARS-CoV-2 pneumonia in rhesus macaques. Nature 2020;2020:093195.

83. An mRNA Vaccine against SARS-CoV-2 Preliminary Report NEJM. Available from: https://www.nejm.org/doi/full/10.1056/ NEJMoa2022483. [Last accessed on 2020 Aug 01].

84. Writer S. COVID-19 Vaccine Trial Starts at 8 Sites; Volunteers are "Fine", say Doctors. Livemint; 2020. Available from: https:/www. livemint.com/news/india/india-s-first-covid-19-vaccine-trial-startsat-up-volunteers-are-fine-says-doctor-11596207102387.html. [Last accessed 2020 Aug 01].

85. Ambikapathy B, Krishnamurthy K. Mathematical modeling to assess the impact of lockdown on COVID-19 transmission in India: Model development and validation. JMIR Public Health Surveill 2020;6:e19368.

\section{How to cite this article:}

Irshad K, Mudassir M, Irshad S, Irshad M. Recent advances in the

knowledge of coronaviruses with special emphasis on severe acute respiratory syndrome coronavirus 2 (SARS-CoV-2). J App Biol Biotech. 2021;9(1):96-103. DOI: 10.7324/JABB.2021.9113 